\title{
O caso da Lumem-paroquia Santíssima Trindade no acolhimento de pessoa em situação de rua em Fortaleza, Ceará
}

\author{
The case of the Lumen-holy Trinity Parish in welcoming a homeless people in Fortaleza, Ceara \\ El caso de la parroquia lumen-santa trinidad al dar la bienvenida a un pueblo sin hogar en Fortaleza, Ceara
}

Recebido: 02/03/2021 | Revisado: 10/03/2021 | Aceito: 19/06/2021 | Publicado: 01/07/2021

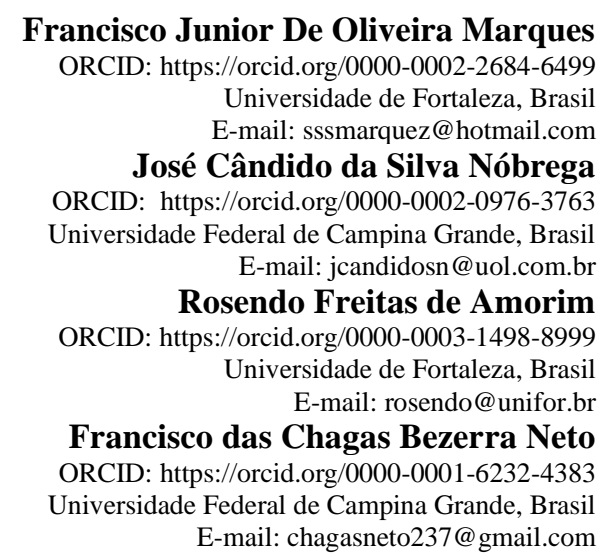

\section{Resumo}

O texto analisa a tensão entre invisibilidade, direitos e solidariedade no contexto de pessoas em situação de rua na cidade de Fortaleza. O estudo da sociologia jurídica de Weber oferecerá conceitos para entender o legalismo estatal como base de uma justiça formal ineficaz à efetivação de direitos mínimos das pessoas em situação de rua. Na ausência do Estado, a Igreja Católica abre suas portas para exercer seu múnus de solidariedade e transformar direito formal em direito substantivo. Nessa perspectiva, este artigo, através da pesquisa exploratória, de natureza qualitativa e quantitativa, método dedutivo, coleta de dados bibliográfico-documental, procedeu-se de modo a realizar uma análise acerca dos dados da pesquisa nacional sobre pessoa em situação de rua, a política nacional para esta população e a experiência concreta de solidariedade da Paroquia Santíssima Trindade. Por fim, pontua-se que os resultados obtidos levam a concluir que o direito e o cuidado com as pessoas em situação de rua exigem auxílio emergencial, mas, sobretudo, capacidade institucional de reconstruir vínculos entre pessoas e sociedade.

Palavras-chave: Direito; Solidariedade; Pessoas de rua.

\begin{abstract}
The text analyzes the tension between invisibility, rights and solidarity in the context of homeless people in the city of Fortaleza. The study of Weber's legal sociology will offer concepts for understanding state legalism as the basis of ineffective formal justice for the realization of the minimum rights of people living on the streets. In the absence of the State, the Catholic Church opens its doors to exercise its solidarity role and to transform formal law into substantive law. In this perspective, this article, through exploratory research, of qualitative and quantitative nature, deductive method, collection of bibliographic-documental data, proceeded in order to carry out an analysis on the data of the national research on people on the street, the national politics for this population and the concrete experience of solidarity of the Paroquia Santíssima Trindade. Finally, it is pointed out that the results obtained lead to the conclusion that the right and care for homeless people requires emergency assistance, but, above all, institutional capacity to reconstruct links between people and society.
\end{abstract}

Keywords: Right; Solidarity; Street people.

\section{Resumen}

El texto analiza la tensión entre invisibilidad, derechos y solidaridad en el contexto de las personas sin hogar en la ciudad de Fortaleza. El estudio de la sociología jurídica de Weber ofrecerá conceptos para entender el legalismo estatal como base de una justicia formal ineficaz para la realización de los derechos mínimos de las personas que 
viven en la calle. En ausencia del Estado, la Iglesia Católica abre sus puertas para ejercer su rol solidario y transformar el derecho formal en derecho sustantivo. En esta perspectiva, este artículo, a través de una investigación explicativa, de carácter cualitativo y cuantitativo, método deductivo, recolección de datos bibliográfico-documental, se procedió a realizar un análisis de los datos de la investigación nacional sobre personas que viven en la calle, la la política nacional para esta población y la experiencia concreta de solidaridad de la Paroquia Santíssima Trindade. Finalmente, se señala que los resultados obtenidos llevan a concluir que el derecho y la atención a las personas sin hogar requiere de atención de emergencia, pero, sobre todo, capacidad institucional para reconstruir los vínculos entre las personas y la sociedad.

Palabras clave: Correcto; Solidaridad; Gente de la calle.

\section{Introdução}

O presente artigo visa analisar a tensão entre invisibilidade, direitos e solidariedade no contexto de pessoas em situação de rua na cidade de Fortaleza. No primeiro item será apresentado pesquisas que descrevem a realidade das pessoas em situação de rua (PSR) no Brasil. No segundo, será focada a realidade da PSR no Ceará, mais especificamente em Fortaleza.

Toda essa realidade é confortada com a produção normativa que garante direitos fundamentais mínimos aos mais necessitados. Entre direito formal e realidade, Marx Weber oferecerá no quarto item do percurso do presente artigo conceitos para entender o porquê desse paradoxo no Estado de direito liberal e capitalista. Finalmente, no quinto e último item emergirá da experiência concreta a ação humanitária da Igreja Católica que assume o compromisso de construir política pública voluntaria para auxiliar as PSR, especialmente, no tempo de pandemia da COVID-19. Neste sentido, pergunta-se: o que significa invisibilidade social frente os direitos formais de um Estado legalista e como a solidariedade preenche o vazio do cuidado em tempos de pandemia da COVID-19?

A metodologia é bibliográfica, elaborada a partir de material publicado em livros, revistas e pesquisa em bases eletrônicas; bem como documental, mediante consulta a legislação e a dados de pesquisas. Quanto aos objetivos, a pesquisa é explicativa, pois identifica e analisa a tensão entre invisibilidade, direitos e solidariedade no contexto de pessoas em situação de rua na cidade de Fortaleza. Quanto à abordagem ao problema apresentado, faz-se um estudo qualitativo e quantitativo. Finalmente, a pesquisa é de natureza teórica.

Tendo em vista a relevância do tema proposto, será realizada uma pesquisa exploratória, que tem por objetivo proporcionar uma maior familiaridade com o problema. Sem a perspectiva de esgotamento do tema, tratar-se-á, sobretudo, acerca das pessoas em situação de rua. Ademais, se utilizará do método de abordagem dedutivo, uma vez que se buscará os resultados a partir da análise geral até concluir de maneira particular a hipótese. Quanto à natureza da pesquisa, esta será quantitativa e qualitativa, buscar-se-á analisar e interpretar os institutos do Direitos Humanos, como forma de chegar à conclusão de que é possível adotar um mecanismo capaz de assegurar os direitos essenciais à pessoa humana, pautado na promoção social e no bem-estar da população.

Quanto ao método de procedimento, atribuir-se-á o método monográfico, partindo de um estudo profundo sobre as pessoas em situação de rua, que podendo esta pesquisa ser considerada representativa de muitos outros ou mesmo de todos os casos semelhantes. Além do mais, quanto aos procedimentos técnicos, se delineará o presente estudo por meio de pesquisa bibliográfica e documental, tendo em vista que se buscará, através da renomada doutrina do direito e periódicos especializados, bem como através da interpretação das leis, a solução para assegurar os direitos inerentes às pessoas humanas.

No presente trabalho, portanto, serão apresentados alguns apontamentos acerca da atuação do Estado liberal e seu arcabouço normativo formal na abordagem de auxílio às PSR. Nesse contexto, a Igreja Católica aparece como uma via alternativa para solidariedade e visibilizarão dos problemas de inclusão social das PSR. 


\section{Pesquisa Sobre Pessoas em Situação de Rua e a Evolução de Assistência}

De acordo com Pesquisa Nacional (WWP, 2016) realizada pelo Ministério do Desenvolvimento Social e Combate à Fome (MDS), em 2008, as pessoas em situação de rua (PSR) totalizavam 31.922. Predominantemente homens (82\%), dos quais $67 \%$ são negros. A maior parte está no mercado informal, trabalhado com material reciclável $(27,5 \%)$, flanelinhas $(14,1 \%)$, construção civil $(6,3 \%)$, carregadores e estivadores $(3,1 \%)$. Para apresentar uma ideia clara do entendimento comum, apenas $15 \%$ é pedinte. No aspecto educacional $74 \%$ são alfabetizados.

A pesquisa aponta ainda os motivos da permanência nas ruas: $35,5 \%$ em razão do alcoolismo ou dicção a droga, $29,8 \%$ perda de emprego e 29, $1 \%$ conflitos familiares. Quanto a procedência, revela-se que $72 \%$ proveem de áreas urbanas, observando que o êxodo rural não é expressivo nesse contexto. Falando-se em permanecia na situação de rua, 48\% da população de rua estava já a mais de dois (02) anos dormindo nas ruas ou em serviços de acolhimento no momento da pesquisa. Ainda, 60\% tinham um histórico de internação em instituições como abrigos, orfanatos, casas de detenção ou hospitais psiquiátrico. A principal razão de procurar abrigos para dormir é a violência (63\%). A rua não aparece como lugar desconfortável, especialmente porque a rua é lugar de liberdade.

Quanto aos vínculos familiares, 51, 9\% possui algum parente residente na cidade em que se encontram, contudo, $40 \%$ não mantem contato com a família. O acompanhamento por familiares é de apenas $10 \%$. A assistência do governo, na ocasião da pesquisa, revelou-se praticamente inexistente, pois $90 \%$ das pessoas em situação de rua afirmam não receber benefícios de órgãos governamentais.

A pesquisa 2008 foi a base sociológica para a formulação de políticas públicas mediante o Decreto 7.053/2009. Essencial para avançar no atendimento ao auxílio às PSR, essa pesquisa, contudo, ainda não representa um censo nacional consolidado dessa realidade. Em 2016, o IPEA realizou um estudo científico estimando da população de rua de aproximadamente 101 mil pessoas (101.854), sendo constatado que 40,1\% estavam em municípios com mais de 900 mil habitantes e 77, 02\% naqueles com mais de 100 mil habitantes, restando apenas 6, 68 em municípios com até 10 mil.

Observe que de 2008 a 2016, o aumento da PSR foi mais de 70\%. O cenário demonstra um crescimento de pessoas com esse perfil exorbitante. É facilmente constatável que a cada ano as ruas são tomadas como habitáculos de parcelas crescente da população brasileira, situação originada por vários fatores, podendo destacar o desemprego, a violência doméstica e social, alcoolismo e dependência química, ausência de vínculos familiares, perda de autoestima, transtorno mentais e outros. Razões bem similares àqueles que se pode ler à luz da pesquisa de 2008.

O governo federal, mediando a Cartilha (SUAS, 2011) de inclusão de pessoas em situação de rua no Cadastro Único para programas sociais, trata de atuar com políticas públicas de erradicação da pobreza, e os números de assistência foi crescendo durante os anos. Contudo, o difícil acesso aos dados e as subestimações dificulta a avaliação da real situação.

O estudo do IPEA 2016 estima que 48.351 pessoas em PRS estão no CADUNICO, o que representa 40\%. Note-se que o Cadastro Único para programas sócias do governo federal é um instrumento de coleta de dados que possibilita a identificação e a caracterização das famílias/indivíduos brasileiros de baixa renda. É também uma importante ferramenta de planejamento de politicais públicas e deve ser utilizado para a seleção de beneficiários e integração de programas sociais do governo federal (Decreto n 6135/2007 e Portaria GM/MDS n 177/2011).

A invisibilidade da PSR ainda é uma marca da realidade brasileira. A situação se aprofundou depois da crise que o Brasil mergulho depois de 2014, e em proporções de calamidade com o momento de pandemia da COVID-2019. Fazendo uma aproximação do objeto de pesquisa desse artigo, o item seguinte quer tratar da situação do especifica da cidade de Fortaleza no Estado do Ceará. 


\section{O Caso de Fortaleza, Epicentro das Pessoas em Situação de Rua no Ceará}

Em 2015 foi realizado pela Secretaria de Trabalho e Desenvolvimento Social (STDS) do Estado do Ceará um Censo e Mapa de Risco Pessoal e Social (CEMARIS). No que se refere as notificações de PSR coletados, chegou-se ao total de 2.033 casos. A grande fortaleza ficou com a maioria, chegando ao número de 1.564 notificações, o que representa 79,9\% (MPCE, 2015). A população de Fortaleza em 2015 estava nas marcas de 2609,716 habitantes, e o censo da população de rua apontou para 1718 homens e mulheres vivendo na rua. Três áreas são as mais críticas. 50\% está localizada no Centro da cidade; $19 \%$ na região da Beira-mar e 16,3\% na região Centro-Bezerra de Menezes.

Após sete anos sem atualização, em fevereiro de 2020 iniciou-se um novo censo, com previsão da Secretaria dos Direitos Humanos e Desenvolvimento Social (SDHDS) de terminar ainda no primeiro semestre de 2020. Contudo, com o avance da pandemia da COVID-19 e o isolamento social criou um novo cenário de imprevisibilidade. Recentes dados apontam dados recentes de 247 pessoas vivendo da Praça do Ferreira (Povo, 2019).

Existem duas pousadas sociais no centro, disponibilizando 200 vagas. A rede socioassistencial conta com dois Centros Pop e um centro de Convivência na região central. Há ainda dois abrigos no Jacareacanga para homens e na Parangaba um abrigo para acolher mulheres e famílias.

O isolamento social pode parecer difícil nos últimos dias, mas a população que vive em situação de rua, em Fortaleza, já vive isolada no cotidiano. O problema social se agrava porque, invisíveis ou ignorados, esses homens, mulheres, crianças e idosos também estão expostos à contaminação pelo novo coronavírus, mas não têm o privilégio nem mesmo de um teto. Para minimizar os riscos, a Secretaria Municipal dos Direitos Humanos e Desenvolvimento Social (SDHDS) preparou um plano de ação que envolve a distribuição de marmitas e a implantação de dois abrigos especiais para atendê-los.

O titular da Pasta, Elpídio Nogueira, ressalta que já houve aumento pela procura dos dois Centros de Referência para População em Situação de Rua (Centros Pop), localizados no Centro e no Benfica, porque, com o fechamento do comércio e outros estabelecimentos por decreto estadual, "diminuiu a entrega de alimentos pela comunidade". Os dois serviços, que seguem normalmente, mas tiveram funcionamento reduzido em duas horas - de $9 \mathrm{~h}$ às $15 \mathrm{~h}$-, vêm recebendo mais de 100 pessoas por dia (Diário, 2020)

O acompanhamento e a ajuda são fundamentais, contudo, é urgente requalificar a ajuda, visto que a absoluta maioria não se sente parte de nada, não participam de movimentos sociais ou atividades associativas $(95,5 \%)$.

Isso mostra a dificuldade de recompor-se na sociedade, perceber-se como parte da família humana e, portanto, reconstruir laços sociais e de construção social. O suporte social deve cuidar de ações que reforcem a autoimagem e a identidade positiva para a assunção de deveres sociais e a reinvindicações de direitos na reconstrução de um projeto de vida.

Essa realidade no contexto brasileiro e, especificamente, no Ceará, demonstra a aguda situação e desafios das PSR. No próximo item será tratado o tema da política nacional para população de rua, sua legislação e os direitos que emergem da política de Estado.

\section{Política Nacional para População em Situação de Rua}

O Decreto $n^{\circ} 7.053 / 2009$ instituiu a Política Nacional para a população em situação de rua. A Constituição de 1988 não prevê expressamente uma política nacional para as pessoas em situação de rua, contudo, manifesta sua relevância para a concretização de direitos fundamentais com a segurança de renda, a convivência familiar, autonomia e a acolhida, além do mínimo existencial. O fundamento desses direitos responsabiliza o Estado para prover saúde (art. 196), educação (art. 205), habitação (art. 182 e 23 IX), proteção a família (art. 226) e assistência social (art. 194 e 203), o que ocorre mediante politicas pulicas. No art. $1^{\circ}$, estabelece o decreto: 
Fica instituída a Política Nacional para a População em Situação de Rua, a ser implementada de acordo com os princípios, diretrizes e objetivos previstos neste Decreto. Parágrafo único. Para fins deste Decreto, considera-se população em situação de rua o grupo populacional heterogêneo que possui em comum a pobreza extrema, os vínculos familiares interrompidos ou fragilizados e a inexistência de moradia convencional regular, e que utiliza os logradouros públicos e as áreas degradadas como espaço de moradia e de sustento, de forma temporária ou permanente, bem como as unidades de acolhimento para pernoite temporário ou como moradia provisória. (Brasil, 2009).

À luz do texto, se estabelece três condições para ser configurada a situação de rua: pobreza extrema, vínculos familiares interrompidos ou fragilizados e inexistência de moradia convencional. Nesse sentido, a situação de rua é uma questão pluridimensional, com fatores estruturais e sócio afetivos. Por essa razão, a própria Política Nacional deixa clara as diretrizes no art. $6^{\circ}$ do decreto:

III - articulação das políticas públicas federais, estaduais, municipais e do Distrito Federal;

IV - Integração das políticas públicas em cada nível de governo;

V - Integração dos esforços do poder público e da sociedade civil para sua execução;

VI - Participação da sociedade civil, por meio de entidades, fóruns

e organizações da população em situação de rua, na elaboração,

acompanhamento e monitoramento das políticas públicas;

VII - incentivo e apoio à organização da população em situação de rua e à sua participação nas diversas instâncias de formulação, controle social, monitoramento e avaliação das políticas públicas. (Brasil, 2009).

Consoante o artigo $2^{\circ}$ do referido decreto, os incisos antecedentes exigem uma ação integradora e descentralizada.

A Política Nacional para a População em Situação de Rua será implementada de forma descentralizada e articulada entre a União e os demais entes federativos que a ela aderirem por meio de instrumento próprio. Parágrafo único. O instrumento de adesão definirá as atribuições e as responsabilidades a serem compartilhadas. (Brasil, 2009).

Um dos fundamentais da República federativa do Brasil é a dignidade da pessoa humana (art. 1, III), e nessa linha, a dignidades só é possível na medida que o Estado possibilita a realização da erradicação da pobreza e da marginalização, e a redução das desigualdades sociais e regionais (art. 3, III). Dessas noções emerge o conceito de mínimo existencial. O ministro Celso de Melo destaca:

A noção de "mínimo existencial", que resulta, por implicitude, de determinados preceitos constitucionais $\left(\mathrm{CF}\right.$, art. $1^{\circ}$, III, e art. $3^{\circ}$, III), compreende um complexo de prerrogativas cuja concretização revela-se capaz de garantir condições adequadas de existência digna, em ordem assegurar, à pessoa, acesso efetivo ao direito geral de liberdade e, também, a prestações positivas originárias do Estado, viabilizadoras da plena fruição de direitos sociais básicos, tais como o direito à educação, o direito à proteção integral da criança e do adolescente, o direito à saúde, o direito à assistência social, o direito à moradia, o direito à alimentação e o direito à segurança. (STF, 2019).

Dessa maneira, a omissão ou insuficiência de oferta do Estado configura violação ao dever de promover a dignidade e eliminar a pobreza por meio de direito sociais (art. $6^{\circ}$ da $\mathrm{CF} / 88$ ). $\mathrm{O}$ art. 203 dispõe que a assistência social será efetivada por meios de políticas públicas. Como garantia de direitos essenciais.

Art. 203. A assistência social será prestada a quem dela necessitar, independentemente de contribuição à seguridade social, e tem por objetivos:

I - a proteção à família, à maternidade, à infância, à adolescência e à velhice;

II - o amparo às crianças e adolescentes carentes;

III - a promoção da integração ao mercado de trabalho;

IV - a habilitação e reabilitação das pessoas portadoras de deficiência e a

promoção de sua integração à vida comunitária; 
V - a garantia de um salário mínimo de benefício mensal à pessoa portadora de deficiência e ao idoso que comprovem não possuir meios de prover à própria manutenção ou de tê-la provida por sua família, conforme dispuser

a lei. (Brasil, 1988).

Essa lista deixa claro os grupos-alvos, contudo, é necessário notar que o art. $2^{\circ}$ da LOAS, com relação a nova redação dada pela Lei ${ }^{\circ} 12.435 / 2011$ amplia:

Art. $2^{\circ} \mathrm{A}$ assistência social tem por objetivos:

I - a proteção social, que visa à garantia da vida, à redução de danos e à prevenção da incidência de riscos, especialmente:

a) a proteção à família, à maternidade, à infância, à adolescência e à velhice;

b) o amparo às crianças e aos adolescentes carentes;

c) a promoção da integração ao mercado de trabalho;

d) a habilitação e reabilitação das pessoas com deficiência e a promoção de sua integração à vida comunitária; e

e) a garantia de 1 (um) salário-mínimo de benefício mensal à pessoa com deficiência e ao idoso que comprovem não possuir meios de prover a própria

manutenção ou de tê-la provida por sua família;

II - a vigilância socioassistencial, que visa a analisar territorialmente a capacidade protetiva das famílias e nela a ocorrência de vulnerabilidades, de ameaças, de vitimizações e danos;

III - a defesa de direitos, que visa a garantir o pleno acesso aos direitos no conjunto das provisões socioassistenciais.

Parágrafo único. Para o enfrentamento da pobreza, a assistência social realiza-se de forma integrada às políticas setoriais, garantindo mínimos sociais e provimento de condições para atender contingências sociais e promovendo a universalização dos direitos sociais. (Brasil, 2011).

Em outro ponto, com maior destaque, o art. $1^{\circ}$ da LOAS conceitua assistência social como sendo: "política de Seguridade Social não contributiva, que provê os mínimos sociais, realizada através de um conjunto integrado de ações de iniciativa pública e da sociedade, para garantir o atendimento às necessidades básicas". E afirma: "trata-se de um direito do cidadão e dever do Estado”. (Brasil, 2011).

Pela cumulação da previsão contida no caput do art. 203 da CF, com a previsão contida no art. $1^{\circ}$ da LOAS, pode-se concluir que a assistência social deverá ser prestada a todos os que dela necessitarem, para a provisão dos mínimos sociais e o atendimento às necessidades básicas de que trata a Lei Federal. A aproximação dos conceitos de "mínimo social" e de “necessidade básica" à noção de "mínimo existencial” constitui o conjunto de circunstâncias e de regras capazes de possibilitar a todos uma vida digna, longe da pobreza e das circunstâncias impeditivas do pleno desenvolvimento da pessoa, em sintonia com as previsões dos arts. $1^{\circ}$, III, e $3^{\circ}$, III, da CF. A assistência social, portanto, deve ser entendida como um direito do cidadão perante o Estado, garantia dos direitos individuais e sociais essenciais à emancipação intelectual, autopromoção e identidade, busca da felicidade e autodeterminação para as realizações pessoais.

A realidade descrita pelas pesquisas e dados nacionais, bem como locais, e a legislação que normatiza a responsabilidade jurídica do Estado abre um abismo entre direito formal e efetivação desses direitos. Qual a razão dessa contradição? O sociólogo Max Weber apresenta em seu estudo socioeconômico as forças reais que guiam o Estado moderno, oferecendo, assim, um arcabouço teórico para entender a atual função de justiça social no Estado liberal capitalista.

\section{A Injustiça Social Fundada em um Estado que Garante Direitos Formais}

A sociedade moderna e seu Estado se organiza a partir da fonte normativa, elaborada de forma racionalmente especializada e atrelada a um sistema intelectual que exige profissionais treinados. Nesse sistema bem articulado e logicamente construído será possível propor a resolução de conflitos sociais e preservação do status quo de paz na sociedade.

O direito, portanto, se manifesta na sociedade como espaço não ambíguo e supremo de regulação social, completamente separado e autônomo do poder e da religião. Na teoria social de Max Weber, o direito se separa do poder e da 
religião como fontes de controle social, pois, o primeiro é lugar de favorecimento de objetivos particulares (Weber, 1968, p. 811) e o segundo pressupõe pressões para sacrificar a generalidade em favor de fins éticos concretos (Weber, 1968, p. 810).

$\mathrm{Na}$ organização social moderna, o Direito assume o controle de toda vida social, não apenas de forma abstrata, mas mediante numa estrutura jurídica altamente especializada que se denomina legalismo. Após anos de cultura social racionalista e axiomas fundamentais reeditados no contexto moderno como lex super omnia, a sociedade moderna implementa um sistema de regras autônomas nas quais são obedecidas porque se acredita que sejam utilizadas de forma racional e indistinta. É esse sistema que dá força ao Estado burocrático moderno, fundado na reinvindicação à obediência e conservação de um sistema de regras racionais. Assim, o direito racional e a dominação legal desenvolveram uma relação simbiótica.

Nesse modelo legalista fundado na construção lógica-sistêmica da lei e na sua organização baseada no corpo de profissionais especializados emergiu um direito de maneira fixa e formal. As facções políticas e econômicas que defenderam políticas substantivas específicas ou resultados econômicos são garantidas pelo estabelecimento de um estado formalista.

A sociologia jurídica weberiana deixa claro a ordem jurídica montado sob o legalismo e a sustentação ao edifício da sociologia econômica que torna o Estado moderno um produtor de políticas de direitos formais. O Estado modernos, alicerce dos atuais Estados contemporâneos, se organizou à luz de um direito bem-acabado com a finalidade de desenvolver o capitalismo. Dois aspectos fundamentais para Weber nessa construção são: a racionalidade do sistema e a liberdade contratual. Para Weber, o capitalismo exige uma organização normativa calculável. O legalismo ofereceu esse ambiente ao capitalismo e lhe deu estabilidade e previsibilidade. Para Weber, o capitalismo não teria tido sucesso se o Estado com sua máquina burocrática jurídica não tivesse oferecido controle dos seus recursos mediante a coação jurídica (Weber, 1968, p. 39).

A proteção do modelo fundamental capitalista das vontades egoístas onde cada qual é obrigado a levar seus interesses individuais adiantes foi fundamental. No capitalismo de mercados puros ninguém é obrigado a preocupar-se com os desdobramentos de suas ações sobre o bem-estar econômico do outro; e essas ação são elevadas a status de bem jurídicos protegidos na sociedade capitalista.

O Estado entra aqui protegendo o bem jurídico do capitalista, sua liberdade e sistema mediante as coações construídas no sistema jurídico estatal e, assim, o Estado fundado no sistema legalista assume um claro papel de legitimidade da dominação capitalista.

Por um lado, o legalismo estabelece um limite legal ao Estado, contudo, por outro, reforça o poder desse mesmo Estado. Esse movimento paradoxal que submete o Estado ao regime de regras, poderia parecer que restringiria o poder do Estado, contudo, ao contrário, lhe dá mais legitimidade. No momento em que o Estado liberal se fortalece, consequentemente, são fortalecidos os capitalistas. Assim, o princípio da imparcialidade formal do direito cria um ambiente propício para autonomia real e substancial aos mais ricos; e a sensação de liberdade pelos direitos formais aos mais pobres garantidos nos textos legais (Weber, 1968, p. 802).

Para Weber essa contradição nascida do legalismo jurídico estatal resulta dos critérios de justiça formal e material e, consequentemente, de uma administração judicial puramente formal. A justiça formal é conveniente para os detentores do poder econômico, pois, é calculável e desencoraja a aplicação de direito como justiça social. Assim escreve Weber (1968, p. 812):

A justiça formal garante liberdade máxima pra que as partes envolvidas defendam seus interesses legais formais. Mas, devido a desigual distribuição de poder, legalizada pelos sistema formal de justiça, esta mesma liberdade produzirá, repetidamente, consequências contrarias (...) às éticas religiosas ou (...) conveniências políticas.

Os elementos de leitura sociológica econômica de Weber nos fazem entender o porquê da paradoxal realidade entre os direitos formais descritos nos diplomas legais e a realidade descrita pela realidade. O Estado liberal cimentado no legalismo 
formal dificilmente poderá oferecer condições reais para a efetivação de direitos sociais. As políticas públicas de PSR continuará contando com a sociedade civil para corrigir o paradoxal sistema do Estado liberal nos termos da leitura socioeconômica de Weber. Nesse sentido, o item seguinte retrata o esforço continuo e, em especial, em tempo de pandemia, da Igreja Católica de produzir inclusão social das PSR.

\section{Igreja Católica, um Lugar de Apoio Humanitário na Inclusão das PSR}

A Obra Lumen de evangelização se consolidou durante a pandemia da COVID-19 como uma das instituições mais solidárias e estruturadas no amparo aos pobres, especialmente as pessoas em situação de rua e dependentes químicos. A Obra é uma comunidade católica fundada em 1989. É composta por crianças, jovens e adultos, unidos num mesmo ideal de amor. A comunidade realiza grupos de oração, projetos de ação social, retiros e diversos eventos de evangelização a fim de louvar a Deus, meditar seus ensinamentos e crescer na fé por meio da prática dos valores evangélicos.

Lumen, em latim, significa "luz". É o que os membros se propõem a ser para o mundo, por meio do carisma, ou seja, buscar ser autênticos discípulos da Luz, missionários inovadores, capazes de promover uma revolução de amor, especialmente, entre os jovens e os mais necessitados, sendo sinais claros da presença de Jesus no cotidiano da vida.

Esse ideário, termos sociológicos, ou carisma, em termos teológico, situa as PSR no centro das atividades da Obra. A instituição disponibilizou gráficos que demonstram a expansão da solidariedade nestes tempos de crise da COVID-19, e se une a oito (8) instituições católicas espalhadas por Fortaleza para acolher mais de 850 homens, mulheres e crianças em situação de rua. A curva crescente de solidariedade demostra a atividade do bem pela Obra Lumen.

Figura 1: Novos acolhimentos da Obra Lumen.

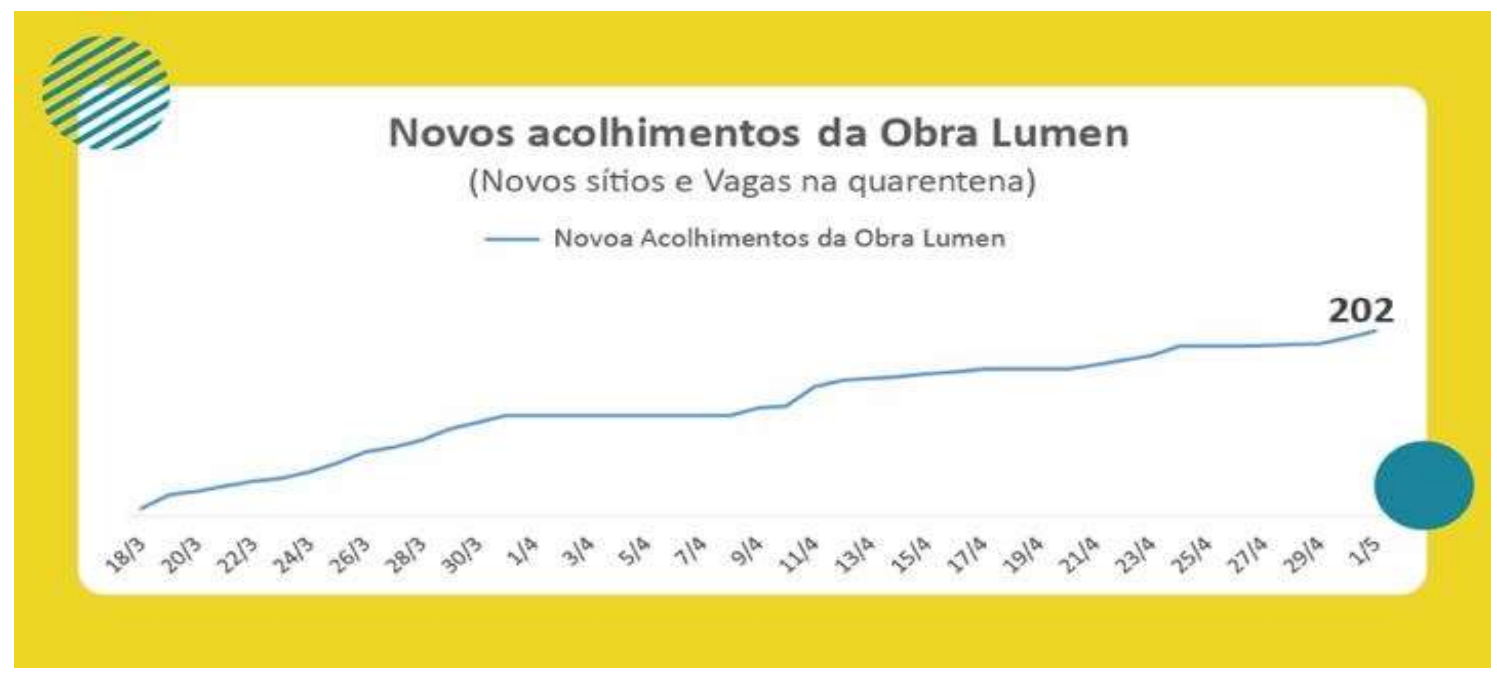

Fonte: CNBB, Regional Nordeste 1, Ceará (2019).

Através das doações, empresas comprometidas e dos participantes do cadastro "Ser Feliz" (Lumen, 2020), Obra já conseguiu distribuir mais de 1.500 cestas básicas e mais de 20 mil marmitas. Impressiona também a quantidade de acolhimento à população mais vulnerável. Foram 202 pessoas em situação de rua que a Obra Lumen deu teto, alugando casas de retiro e provendo alimentação e orientação. Em parceria com outros Carismas pelo Brasil, através do projeto "Com Deus Tem Jeito", o número de acolhidos saltou para mais de 800 irmãos de rua. 
Figura 2: Ações Ser Feliz.

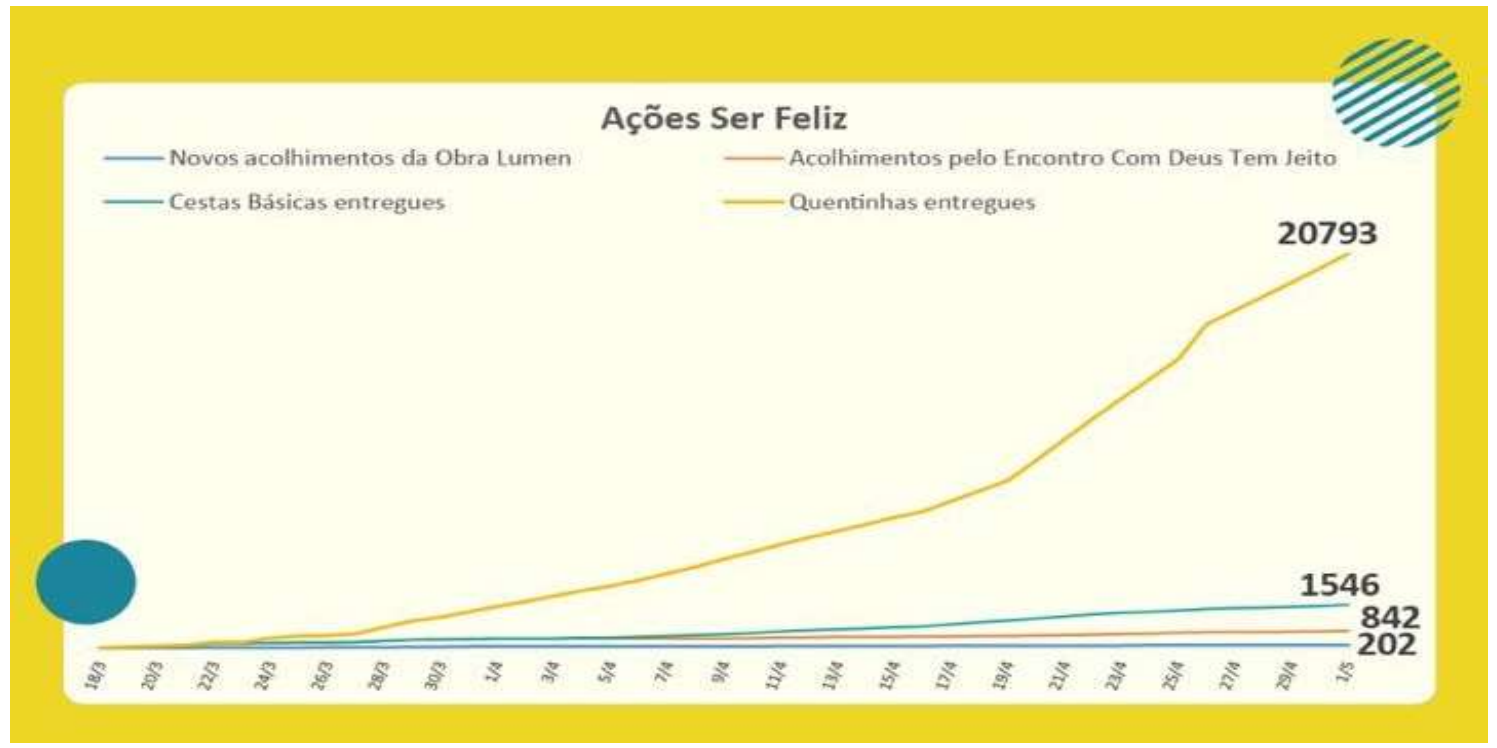

Fonte: CNBB, Regional Nordeste 1, Ceará (2019).

Em parceria com a Obra Lúmen, a Paróquia Santíssima Trindade, que tem sua Igreja Matriz no Conjunto Prefeito José Walter, em Fortaleza, Ceará, acolheu seis (06) moradoras de Rua nas suas dependências na primeira turma entre os dias 13 a 27 de abril de 2020. Esse programa tem como objetivo receber PSR durante 15 para vivencia da quarentena, ou período de monitoramento dos sinais da COVID-19. Após esse período e certificando-se da condição de saúde boa, as PSR são encaminhadas para um centro de longa permanência para continuar o processo de inserção na sociedade.

Sem sobra de dúvida, esse é o maior desafio no diálogo com as PSR, ou seja, recuperar nelas o desejo de retomar vínculos sociais, reconstruir a confiança e o estilo de vida da sociedade. As PSR encontram a rua como lugar de liberdade, como visto acima nos indicadores de pesquisas. Ritmo de vida, compromissos, horários, e vínculos são estruturas psicossociais que já não fazem parte da construção de mundo e de futuro dessas pessoas. A rua é a sua zona de conforto e, fora dela, há uma zona cinzenta de insegurança.

Um marco fundamental que diferencia os lugares instrucionais de acolhimento do Estado e as casas de acolhida da Igreja é o suporte do imaginário psicossocial que se reestabelece na memória afetiva das PSR. O local, o ambiente e as pessoas são a nova zona de conforto que permite a possiblidade da reconstrução do delicado quebra-cabeças que as PSR devem montar para a retomada de vínculos e sentido de mundo social.

É importante ter em conta todos os detalhes na experiência desse choque de mundos das PSR. De fato, há dois mundos em conflito. De um lado, a liberdade conhecida da rua; e do outro, a estrutura social como promessa de reconstrução de vida. A experiência na Paroquia pode oferecer um suporte psicosocio-espiritual nessa passagem, pois, as internas se policiavam no vocábulo, no comportamento, na forma de relacionamento; e tudo em razão de estar dentro de uma Igreja. Elas diziam: "temos que nos comportar, pois estamos na casa de Deus". Observe-se que um detalhe, talvez imperceptível, pode introjetar, de forma mais rápida, comportamentos de respeito, cooperação social e fiducial comunitário.

Além do ambiente, a construção de vínculos nas casas de acolhida, e especificamente na experiência da Paroquia, só pode ser possível pelos assistentes socais que acompanhavam o grupo. Denomina-las de assistentes sociais é demasiadamente pouco. Essas mulheres fazem de sua vida uma total doação para a reconstrução de vínculos pessoas e sociais das PSR.

Lívia Chagas, 27 anos, é a jovem que assumiu a responsabilidade de estar com as pessoas em situação de rua no período da quarentena na Igreja Santíssima Trindade, em Fortaleza. Sua trajetória no trabalho voluntario indicou em 2008, quando ingressa na Obra Lumen e, em 2016 opta por uma vida missionaria para dedicar-se exclusivamente a ação social e 
religiosa. Em 2018 faz seus votos na vida consagrada, ou seja, incorpora-se juridicamente pela promessa de vida à Obra Lumen. A missão ou carisma que impulsiona Lívia à dedicar-se a este estilo de vida é "viver o amor esponsal com Jesus abandonado [e] encarnado nos mais pobres" (Chagas, 2020).

A ação solidaria fundada numa narrativa religiosa desterritorializada os lugares de vida dos assistidos, movendo-os da desproteção ao vinculo de cuidado e proteção familiar. Como afirma Chagas (2020):

Quando, enquanto Igreja os acolhemos, acredito que podemos passar uma pertença de família em Deus, que tem também a sua contribuição indispensável para toda a sociedade, nesse gesto, gerando a cultura do encontro da sociedade com eles, rejeitando a cultura da indiferença e testemunhando a graça de sermos felizes fazendo os outros felizes, a partir dos sentimentos de Cristo.

Essa perspectiva fica gravada na vida e história das pessoas em situação de rua que são acolhidas nas Igrejas e associais afins. Nesse sentido, três relatos de PSR, Deusilene Ribeiro (Lene), Adriele Tabosa e Gardenia Delfino, convergem para a mesma razão no diferenciar uma acolhida pelo Estado e pela Igreja. Ou seja, no acolhimento realizado pela Igreja, destacam-se sentimentos de carinho, cuidado e família (Ribeiro, 2020). Segundo Adrielle Ribeiro (2020): "É diferente [a acolhida no Estado daquela na Igreja]. O Estado cuida oferecendo tratamento de medicação de comprimido, por exemplo, como é o caso do CAPS. E um ambiente da igreja, a gente tem muito mais... A gente se sente em uma família."

Gardênia Delfino (2020) é ainda mais contundente quando aponta não apenas métodos diferentes, mas também, abordagens que podem mesmo prejudicar a recuperação dos assistidos, bem como retomados dos vínculos familiares: "Via coisas acontecendo em abrigo da prefeitura, que não fazia a gente conseguir combater as drogas, fora o ambiente de muita confusão. Na igreja é diferente, a gente aprende a respeitar mais os irmãos e as outras pessoas".

Definitivamente, é nesse lugar psicosócio-espiritual que a invisibilidade vai perdendo sua força e o amor como laço de confiança vai se construindo para que as PSR possas reacreditar em convívio social. A dura realidade das existências dessas pessoas não pode ser superadas apenas com ajuda financeira ou abrigo físico; esses são a porta de entrada. $\mathrm{O}$ retorno para o convívio social e a saída das ruas apenas será possível com a recuperação das almas (em grego psiché), dos mundos interiores que religam as pontas dos fios das histórias pessoas e reconstroem sentido de vida comunitária.

\section{Considerações Finais}

Ante todo o exposto, percebe-se que no ponto de interseç̧ão entre o conceito de identidade como metamorfose humana e de representações sociais, discutiu-se sobre dados estatísticos, marco jurídico dos conceitos de PSR, situação local de Fortaleza, direitos formais de impacto superficial na vida das pessoas e, finalmente, experiências de acolhimento que marcam novo paradigma da abordagem com as PSR. Invisibilidade e solidariedade se dissipam frente a uma nova abordagem que tratam direitos como recuperação concreta de pessoas e não como lista de boas intenções.

No que se refere às pessoas em situação de rua, estas tipificações surgem sob a feição de apreendê-las como vagabundas, sujas, loucas, perigosas e coitadas - que suscitam atitudes que vão da total indiferença à hostil violência física. Essa construção de identidade pouco tem a ver com a realidade. Mas sem dúvida, tem a ver com as consequências de invisibilidade, pouca solidariedade e abordagem superficial do Estado.

$\mathrm{O}$ avanço consistente advindo dessa pesquisa mostrou que é necessário apoiar iniciativas e abordagem nova e corajosas de organizações sociais capazes de tratar com humanidade o desastre humanitário das PSR. A pesquisa perde sua força em razão dos poucos dados tanto das instituições estatais como das organizações religiosas que pudessem oferecer um perfil mais realista dessa abordagem humanitária de recuperação de vínculos das PSR. 
Dessa maneira, como forma de assegurar, de forma eficaz, o bem-estar das pessoas em situação de rua, acreditamos que investigações como esta devem ser prosseguidas. Sendo assim, como sugestão para continuidade de discussões nesse sentido, analisar, à luz dos Direitos Humanos, de que modo as inovações normativas tratam acerca das pessoas em situação de rua, contribuirá para o fortalecimento e planejamento de estratégias de atenção a este público, assim como desenhar e formular novos e mais efetivos caminhos em direção à efetivação dos direitos inerentes as pessoas em situação de rua.

\section{Referências}

Braga, L. Censo da população em situação de rua em Fortaleza começa a ser feito em fevereiro. Jornal do Povo, Fortaleza, https://www.opovo.com.br/noticias/fortaleza/2020/01/28/censo-da-populacao-em-situacao-de-rua-em-fortaleza-comeca-a-ser-feito-em-fevereiro.html.

Brasil. Constituição (1988). Constituição da República Federativa do Brasil: promulgada em 5 de outubro de 1988. http://www.planalto.gov.br/ccivil_03/constituicao/constituicao.htm.

Brasil. (2009). Decreto n. 7.053, de 23 de dezembro de 2009. DOU de 24.12.2009. Poder Executivo, http://www.planalto.gov.br/ccivil_03/_Ato20072010/2009/Decreto/D7053.htm.

Brasil. (2011). Lei n. 12.435, de 6 de julho de 2011. DOU de 7/7/2011. Poder Executivo,. http://www.planalto.gov.br/ccivil_03/_Ato20112014/2011/Lei/L12435.htm.

Chagas, L. C. (2020). Lívia Cartaxo Chagas: depoimento [20 maio]. Entrevistador: Francisco Marques, Fortaleza: Lumen-CE. Registro escrito em whatsup. Entrevista concedida ao Projeto Obra Lumen de Fortaleza-CE.

Conselho Nacional do Ministério Público (CNMP). (2015). Guia de atuação ministerial: devesa dos direitos das pessoas em situação de rua. CNMP.

Delfino, A. G. (2020). Ana Gardênia Delfin: depoimento [20 maio]. Entrevistadora: Liva Cartaxo Chagas, Fortaleza: Lumen-CE. Registro escrito em whatsup. Entrevista concedida ao Projeto Obra Lumen de Fortaleza-CE.

Lumem. Projeto Ser Feliz, https://www.lumenserfeliz.com.

Ministerio da Cidadania. Sistema de Desenvolvimento Social (SAGI). (2019). População em situação de rua no Brasil: o que os dados revelam? Monitoramento SAGI, Série Relatos de Casos. Brasília, Ministério da Cidadania. https://aplicacoes.mds.gov.br/sagi/portal/index.php?grupo=228.

Ministério do Desenvolvimento Social, Word Without Poverty (WWP). (2015). A pesquisa nacional sobre a população em situação de rua. Série WWP relatos de uso de M\&A, por Roberto Cartizo. https:/wwp.org.br/wp-content/uploads/2016/11/Pesquisa-Nacional-sobre-a-Popula\%C3\%A7\%C3\%A3o-de-RuaRelato-de-Uso-WWP__-PORT.pdf.

Ministério do Desenvolvimento Social. (2011). Inclusão das pessoas em situação de rua no cadastro único para programas sociais do governo federal (v. 1). Brasília. https://www.gesuas.com.br/blog/pessoas-em-situacao-de-rua-no-cadastro-unico-para-programas-sociais.

Ministério do Planejamento, Desenvolvimento e Gestão. Instituto de Pesquisa Econômica Aplicada (IPEA). (2016). Estimativa da população em situação de rua no Brasil. Texto para discursão 2246. Brasília, Ipea. http://www.ipea.gov.br/portal/index.php?option=com_content\&view=article\&id=28819.

Ministério Público do Ceará (MPCE). (2015). População em situação de rua. Guia de atuação do MPCE.

Paulino, N. (2020). Dois abrigos emergenciais receberão população de rua em Fortaleza. Jornal Diário do Nordeste, Fortaleza. https://diariodonordeste.verdesmares.com.br/editorias/metro/dois-abrigos-emergenciais-receberao-populacao-de-rua-em-fortaleza-1.2226405

Ribeiro, M. D. B. (2020). Maria Deusilene Barros Ribeiro: depoimento [20 maio]. Entrevistadora: Liva Cartaxo Chagas, Lumen-CE. Registro escrito em whatsup. Entrevista concedida ao Projeto Obra Lumen de Fortaleza-CE.

STF. (2011). Recurso Extraordinário com Agravo. AG. REG. AgR ARE 639.337. Relato: Ministro Celso de Mello. Dje n. 177. Divulgação 14/09/2011. http://redir.stf.jus.br/paginadorpub/paginador.jsp?docTP=AC\&docID=627428.

Barbosa, M. A. L. (2020). Maria Adrielle Leitão Barbosa: depoimento [20 maio]. Entrevistadora: Liva Cartaxo Chagas, Lumen-CE. Registro escrito em whatsup. Entrevista concedida ao Projeto Obra Lumen de Fortaleza-CE.

Weber, M. (1968). Economy and Society. An outline of interpretative sociology. Edited by Guenther Roth and Claus Wittich. Los Angeles, University of California Press. https://books.google.com.br/books?id=MILOksrhgrYC\&printsec=frontcover\&hl=pt-BR\&source=gbs_ge_summary_r\&cad=0\#v=on epage \&q\&f=false. 